\title{
FISCALIZAÇÕES NAS OFICINAS DE COSTURA: ELEMENTOS SOBRE A POLÍTICA DE ENFRENTAMENTO AO TRABALHO ESCRAVO
}

\author{
INSPECTION PROCEDURES IN GARMENT WORKSHOPS: ELEMENTS ABOUT \\ POLICIES FOR CONFRONTING SLAVE LABOR
}

Maíra Costa Etzel ${ }^{1}$

\begin{abstract}
RESUMO
O presente artigo traz um panorama do conceito de trabalho escravo no Brasil e da política de enfrentamento ao crime existente no país, com foco nas ações fiscais que ocorrem nas oficinas de costura em São Paulo. O contexto do estudo é a cidade de São Paulo, que tem sido palco de denúncias de trabalho escravo na indústria têxtil desde o início dos anos 1990. Passados trinta anos, a condição degradante de trabalho dos imigrantes na costura ainda persiste, apesar do amadurecimento das ações de enfrentamento desse problema realizadas pelas organizações da sociedade civil e do poder público. Visto que os trabalhadores ocupantes da base da cadeia produtiva do setor têxtil são na maioria imigrantes latino-americanos, com destaque para os bolivianos, este estudo busca incorporar ao debate elementos acerca da percepção de trabalhadoras da Bolívia em relação às ações de fiscalização nas oficinas de costura.
\end{abstract}

Palavras-chave: trabalho escravo, fiscalização do trabalho, oficinas de costura, imigração boliviana.

\begin{abstract}
This article provides an overview of slave labor's concept in Brazil and also brings light to the public policy for confronting slave labor, focusing on inspection procedures to combat slave labor in textile factories. The study is based in São Paulo, where constant denunciation against slave labor has taken place within the textile industry since the 1990s. Thirty years later, degrading work conditions still persists, despite the actions taken by civil society organizations and public authorities to combat this problem. Since the majority of the workers in garment workshops is composed by Latin Americans immigrants, specially Bolivians, the present study seeks to incorporate perception elements of four Bolivian women about inspection procedures in garment workshops.
\end{abstract}

Keywords: slave labor, labor inspection, garment workshop, bolivian immigration.

\section{INTRODUÇÃO}

A cadeia produtiva do setor têxtil é longa e pulverizada. Em sua base estão as pequenas oficinas de costura, comumente sem registro jurídico e ocupadas por imigrantes internacionais com contratos de trabalhos informais, realizados de forma oral e por vezes descumpridos. Conforme veremos ao longo deste texto, determinadas condições de trabalho vigentes nesses locais podem ser configuradas como de trabalho escravo. Na cidade de São Paulo, aqueles que se encontram na base da cadeia de vestuário são majoritariamente imigrantes latino-americanos, com destaque para a população vinda da Bolívia. Por essa razão, optamos pela

1 Graduada em Ciências Sociais pela Universidade de São Paulo (USP) e mestre em Políticas Públicas em Direitos Humanos pela Universidade Federal do Rio de Janeiro (UFRJ). 
realização de entrevistas com mulheres bolivianas, mas vale notar que o país de origem não é um elemento explicativo dos fluxos migratórios para as oficinas de costura (CÔRTES, 2013) e que não há uma "aptidão natural" dos bolivianos para esse ofício, tampouco uma relação direta de indivíduos dessa nacionalidade às condições de trabalho escravo. Pessoas de outros lugares, como Equador, Paraguai e Peru também estão alocadas na costura e já foram resgatadas do trabalho escravo.

Por sua vez, a apresentação de falas de mulheres bolivianas se deve ao fato de as entrevistas terem sido realizadas durante a dissertação de mestrado ${ }^{2}$, cujo tema envolvia gênero e trabalho escravo. Neste artigo, contudo, não iremos adentrar as questões referentes ao gênero dos trabalhadores ${ }^{3}$, mas em estudos futuros e de maior abrangência será importante verificar se a visão a respeito das ações fiscalizatórias é alterada de acordo com variáveis de gênero e de nacionalidade.

Cabe ressaltar que foram entrevistadas quatro mulheres em um amplo universo de imigrantes, ou seja, não há intenção de generalizar a opinião delas a toda comunidade residente em São Paulo. O contato com as trabalhadoras se deu por meio de Quilla, nossa mediadora de campo, boliviana pesquisadora e militante na defesa dos direitos dos imigrantes na cidade de São Paulo. Com ela, fomos às casas das outras mulheres e, em encontros posteriores, foi possível realizar entrevistas com cada uma delas.

Nas linhas a seguir, faremos uma discussão do conceito de trabalho escravo, seguida do histórico da política pública de enfrentamento ao crime, com foco nas fiscalizações, e por fim apresentaremos a visão das quatro trabalhadoras sobre o tema.

\section{CONCEITO DE TRABALHO ESCRAVO}

O crime de "Reduzir alguém à condição análoga à de escravo" está presente no artigo 149 do Código Penal Brasileiro desde 1940. Apesar disso, o decreto-lei pouco servira de instrumento de luta e reivindicação em prol dos trabalhadores, por não explicitar o significado de submeter alguém à condição análoga à de escravo. Apesar de os movimentos sociais fazerem uso da categoria de trabalho escravo para denunciar as condições vigentes no campo desde os anos 1970, foi apenas em 1995 que o então Presidente da República Fernando Henrique Cardoso reconheceu formalmente a existência do fenômeno no Brasil ${ }^{4}$.

Em 2003 a redação do artigo 149 foi alterada, e a condição de trabalho análoga à de escravo passou a ser tipificada quando da presença de pelo menos um dos quatro elementos a seguir:

2 Trabalhadoras em movimento: bolivianas nas oficinas de costura em São Paulo, defendida no Programa de Pós-Graduação em Políticas Públicas em Direitos Humanos, da Universidade Federal do Rio de Janeiro.

3 Neste artigo não utilizaremos o gênero e a nacionalidade das entrevistadas como variáveis da análise. Para o enfoque nas relações de gênero, ver: ETZEL, Maíra. Mulheres bolivianas em São Paulo: notas sobre migração, filhos e violência. In: FIGUEIRA, Ricardo. PRADO, Adonia; GALVÃO, Edna (Org.). Escravidão: moinho de gentes no século XXI. Rio de Janeiro: Mauad X, 2019, cap. 14.

4 De acordo com Figueira (2011), por meio do extinto Ministério da Reforma e do Desenvolvimento Agrário (MIRAD), em meados dos anos 1980, o Estado brasileiro já teria recorrido em seus relatórios à categoria “escravidão", dando legitimidade ao termo. Em 1992, continuou o autor, Celso Amorim - então embaixador do Brasil na Organização das Nações Unidas (ONU) -, diante de denúncias de "trabalho forçado" por parte da Comissão Pastoral da Terra (CPT) e da Ordem dos Advogados do Brasil (OAB), confirmou a existência do problema em sessão da ONU na Suíça. 
- trabalho forçado, que representa a atividade exigida sob ameaça de qualquer punição, com cerceio da liberdade do trabalhador por meio de isolamento geográfico, ameaça física, moral ou psicológica ou pela retenção de documentos;

- servidão por dívida, que ocorre em situações nas quais o trabalhador contrai dívidas por meio de cobranças indevidas e não consegue quitá-las. Esse tipo de servidão é comum quando o empregador passa a cobrar pela viagem do trabalhador - que na maioria das vezes é migrante -, pelo uso de equipamento de proteção individual ou quando o trabalhador tem acesso apenas a um local de compras, em que os produtos são superfaturados;

- jornada exaustiva, que se refere à submissão a um ritmo de trabalho intenso, sem pausa ou descanso semanal, colocando em risco a saúde física ou mental do trabalhador, não se restringindo apenas ao número de horas trabalhadas. Exemplos de jornada exaustiva podem ser vistos principalmente em atividades laborais cuja remuneração depende de maior produção diária, como é o caso do pagamento por peça nas oficinas de costuras;

- condições degradantes, que são caracterizadas quando há descumprimento dos direitos fundamentais do trabalhador, em que se constata a precariedade das condições de higiene, segurança, saúde, moradia, alimentação, saneamento, entre outros.

De acordo com a definição anterior, não é necessário suprimir a liberdade do sujeito para a caracterização do crime, visto que a retirada da dignidade também coisifica e instrumentaliza o ser humano. Segundo a pesquisadora Siobhán McGraph (2013), a legislação brasileira carrega o mérito de trazer uma abordagem multidimensional para a definição de trabalho escravo, como forma de escapar da dicotomia entre trabalho livre e não livre. O artigo 149 vai ao encontro da ideia de espectro de exploração, que permite a análise das relações trabalhistas com base em dois polos opostos: trabalho decente e trabalho forçado, estando a negação sistemática de direitos localizada no espaço entre ambos. Não se trata de níveis hierárquicos, mas de tipos diferentes de condições degradantes e de restrição de liberdade experimentados pelos trabalhadores e trabalhadoras.

É importante notar que o trabalho escravo não deve ser considerado uma categoria deslocada das demais relações de trabalho vigentes no sistema capitalista. Como apontou o economista Vitor Filgueiras, "na ausência de regulação da relação capital/trabalho, a busca pelo lucro traz a potencialidade de existência do trabalho escravo, independentemente de sua proibição legal" (apud FIGUEIRA; PRADO; GALVÃO, 2015, p. 135). No caso do setor têxtil, conforme mencionado no relatório produzido pela primeira Comissão Parlamentar de Inquérito para Apurar a Exploração de Trabalho Análogo ao de Escravo:

Diversos fatores podem caracterizar todo esse processo como trabalho análogo à escravidão. São eles: a forma como são recrutados na Bolívia, com falsas promessas de salário e bem-estar; confinamento para que paguem as dívidas com seu trabalho; impossibilidade de comunicação; retenção de documentos e de dinheiro; ameaças de denúncia ao poder público sobre sua situação de indocumentado; jornada de trabalho excessiva; alta rotatividade do local de instalação das oficinas de costura; condições totalmente insalubres de trabalho. (SÃO PAULO, 2006, p. 28).

Nas oficinas de costura, que são muitas vezes o local de moradia dos trabalhadores imigrantes, as condições comumente encontradas pela fiscalização do trabalho são: habitação multifamiliar; alojamentos precários, sem cama, com colchões improvisados, mofados, com cortinas para a divisão dos cômodos; armazenamento de alimentos em locais impróprios e sem refrigeração; chuveiros elétricos desligados; instalação sanitária precária e insuficiente para 
a quantidade de trabalhadores; cadeiras improvisadas; máquinas de costura sem aterramento elétrico; ausência de extintor de incêndio; espaços mal iluminados e pouco ventilados e ausência de refeitório. Tais fatores ilustram uma situação em que inexistem condições mínimas de saúde 5 e de segurança e que podem caracterizar condições degradantes de trabalho.

\section{POLÍTICA PÚBLICA E A DINÂMICA DAS FISCALIZAÇÕES}

O reconhecimento da existência de trabalho escravo no território brasileiro foi o ponto de partida para que o Estado criasse políticas públicas com o objetivo de coibir e erradicar o problema. A primeira delas, em 1995, foi o estabelecimento do Grupo Executivo de Repressão ao Trabalho Forçado (GERTRAF), uma "tentativa de articulação interinstitucional para lidar com o tema" (BRASIL, 2013, p. 30). Esse grupo, oito anos depois de sua concepção, foi substituído pela Comissão Nacional de Erradicação do Trabalho Escravo (CONATRAE), espaço institucionalizado que congrega "pessoas historicamente engajadas em suas práticas no combate ao trabalho escravo dentro de suas instituições" (BRASIL, 2013, p. 51-56), com representantes dos três poderes e da sociedade civil.

No ano de 1995 também foi instituído o Grupo Especial de Fiscalização Móvel (GEFM), responsável por verificar as denúncias de trabalho escravo em todo território nacional. O GEFM é ligado à Subsecretaria da Inspeção do Trabalho, que fazia parte do extinto Ministério do Trabalho e Emprego e atualmente está vinculada ao Ministério da Economia. O grupo móvel é coordenado por auditores fiscais do trabalho e composto por profissionais de diversos órgãos, tais como o Ministério Público do Trabalho, o Ministério Público Federal, a Defensoria Pública da União, a Polícia Federal e a Polícia Rodoviária Federal, cada qual com sua atribuição. À época de sua criação, essa combinação trouxe inovação para a política de enfrentamento ao trabalho escravo, tornando-se referência internacional.

As fiscalizações e a consequente repressão quando do flagrante das condições de trabalho escravo também podem ser realizadas de forma regionalizada. Os auditores fiscais do trabalho lotados nas Superintendências Regional do Trabalho atuam por meio de denúncias apesar de não estarem restritos a elas -, realizam investigações e planejam operações de resgate. Uma vez realizado o flagrante de trabalho escravo, esses profissionais realizam o cálculo da rescisão contratual por justa causa - a fim de garantir o pagamento dos direitos trabalhistas no ato do resgate -, emitem a carteira de trabalho e as guias do Seguro-Desemprego para os trabalhadores resgatados. Além disso, estes recebem prioridade na fila do Programa Bolsa Família e, se desejarem, podem ser reencaminhados a seu local de origem (BIGNAMI apud VELLOSO; FAVA, 2011).

Outro encaminhamento possível aos casos de trabalho escravo é realizado pelos procuradores do trabalho, que atuam na responsabilização dos empregadores. Esses profissionais podem construir o Termo de Ajuste de Conduta, acordo assinado pelo empregador que prevê o pagamento de multas e o estabelecimento de metas para que o crime não volte a ocorrer. Caso não haja acordo, entram com Ação Civil Pública na Justiça do Trabalho, pedindo indenização relativa a danos morais coletivos e individuais causados e aos direitos trabalhistas não respeitados. Outra possibilidade é o bloqueio dos bens dos empregadores caso estes se neguem a pagar o montante devido aos trabalhadores no momento da operação de resgate junto aos auditores ficais do trabalho.

\footnotetext{
5 Tais condições contribuem para a alta incidência de doenças pulmonares entre os costureiros, especialmente a tuberculose (MARTINEZ, 2010).
} 
De acordo com o sociólogo Tiago Côrtes (2013), as operações de fiscalização passaram a se pautar pelas cadeias médias e longas, em que eram encontradas empresas capazes de se responsabilizar pelas condições de trabalho encontradas. Isso porque as empresas podem controlar a capacidade produtiva de seus fornecedores e têm a responsabilidade de verificar se estes vão transferir suas encomendas, afinal, como ressaltou Mercante (2015), são elas as detentoras do poder econômico que dirige a cadeia e as responsáveis por fornecer a peça piloto, impor correções, prazos, valores e procedimentos de pagamento.

É preciso lembrar que nem todas as oficinas de costura flagradas com trabalho escravo fazem parte produtiva de grandes marcas do setor têxtil. Quando isso acontece, o percurso para a utilização de mão de obra entre as grandes empresas é semelhante: as tomadoras finais do serviço contratam confecções para produzirem suas peças, e esses fornecedores diretos repassam as encomendas para oficinas menores, a fim de reduzir seus custos. Ocorre que tais oficinas adotam a mesma estratégia das confecções e transferem a encomenda para outras, muitas vezes irregulares ou clandestinas, onde há maior probabilidade de incidência de trabalho escravo. Ao fim e ao cabo, as peças produzidas pelas diversas oficinas chegam às lojas como se tivessem sido feitas exclusivamente pelos fornecedores diretos (REPÓRTER BRASIL, 2016a, p. 4).

Por outro lado, as oficinas que utilizam mão de obra escrava podem também produzir peças para os comércios populares das cidades. O pesquisador Bruno Miranda (2016) apontou que na cidade de São Paulo existe uma segmentação do mercado de roupas, em termos de desenho e qualidade, e descreveu a tipificação dos circuitos de produção de vestuário na capital paulista elaborada pela geógrafa Cristina Silvana em sua tese de doutoramento. O primeiro é o circuito superior, correspondente às grandes marcas que ditam a moda e tem como fornecedores diretos confecções, principalmente de brasileiros, ou ainda importam roupas da China e do Sudeste Asiático e vendem para as classes média e alta. O segundo, identificado como circuito marginal superior, é composto por comerciantes dos bairros do Bom Retiro e Brás, no Centro de São Paulo. Em geral, os proprietários coreanos ou brasileiros de lojas contratam diretamente oficinas de bolivianos, paraguaios, peruanos e brasileiros, em menor escala, e a venda das peças nas lojas destina-se normalmente ao atacado. Por fim, existe o circuito inferior, em que as peças são confeccionadas por pequenos gestores de oficinas de costureiros bolivianos, paraguaios e peruanos, que vendem na Feirinha da Madrugada ${ }^{6}$, localizada no bairro do Brás. Esses produtos são destinados a comerciantes ambulantes de todo o Brasil (SILVANA, 2012 apud MIRANDA, 2016).

Desse modo, podemos afirmar que as operações de fiscalização priorizam o circuito superior. Essa medida tem como estratégia a indução de mudanças de postura por parte da classe empresarial, que, a fim de evitar represálias, passa a cumprir com obrigações antes negligenciadas e a criar novos mecanismos de controle em toda a cadeia produtiva. A fim de informar aos consumidores as medidas que as principais grifes e os grandes varejistas vem tomando para evitar que suas peças sejas costuradas por mão de obra escrava, o aplicativo Moda Livre, desenvolvido pela ONG Repórter Brasil, avaliou as ações de 123 marcas. De acordo com as informações do Moda Livre, foram encontradas no total 43 ocorrências de trabalho escravo nesse setor em todo o território nacional, sendo a capital paulista e a região metropolitana de São Paulo os locais com maior concentração de casos.

Para nos aproximarmos dessa realidade, exemplificamos alguns casos: em 2010, a rede Marisa foi autuada pelas condições de trabalho de 16 bolivianos e um peruano (FILGUEIRAS

\footnotetext{
6 A feira funciona de segunda a sábado das $3 \mathrm{~h}$ às $10 \mathrm{~h}$. O local atrai todos os dias aproximadamente 25 mil pessoas. Além do espaço cedido pela prefeitura aos feirantes, há nos arredores o comércio informal de rua.
} 
apud FIGUEIRA; PRADO; GALVÃO, 2015). Nesse mesmo ano, 15 costureiros bolivianos foram resgatados em uma oficina "quarteirizada" que confeccionava coletes para os recenseadores do Instituto Brasileiro de Geografia e Estatística (IBGE). Em dois flagrantes ocorridos em 2010 e 2011, a Pernambucanas foi condenada por submeter 31 pessoas - provenientes da Bolívia, do Paraguai e do Peru - a condições análogas à de escravo. A Zara, do Grupo Inditex, em 2011, foi responsabilizada por três oficinas de costura de fornecedores onde foram resgatados 67 bolivianos e peruanos (REPÓRTER BRASIL, 2016a). Em 2013, o grupo varejista Restoque, da marca John John, foi condenado por 28 bolivianos em condições de trabalho análogas à de escravo. Em ações fiscais realizadas entre 2013 e 2014, a M5 Indústria e Comércio, proprietária da marca M.Officer, foi condenada após oito trabalhadores bolivianos serem encontrados em condições análogas à de escravo. Em 2014, foi a vez da Renner, que foi responsabilizada por 37 costureiros bolivianos, dentre os quais havia 21 homens, 15 mulheres e uma adolescente. No mesmo ano, a Seiki foi condenada pelo trabalho de 17 bolivianos resgatados, dentre os quais havia uma adolescente de 15 anos, grávida de sete meses. Os casos seguem aparecendo ano a ano.

De acordo com dados da Subsecretaria da Inspeção do Trabalho sistematizados pela ONG Repórter Brasil (2020), entre os anos de 1995 e 2018, 257 pessoas foram resgatadas do trabalho escravo na confecção têxtil apenas no município de São Paulo. Tais ações de resgate têm o papel fundamental de interromper a situação de violação de direitos humanos na qual os trabalhadores são encontrados e garantir o pagamento dos direitos trabalhistas que lhes foram negados. Cabe notar que o consentimento dos trabalhadores não descaracteriza o crime de trabalho escravo, uma vez que considerar a suposta aceitação em relação às condições de trabalho em que são submetidos representaria um retrocesso, visto que, por diversos motivos, em que pese principalmente a necessidade concreta, não é possível afirmar que se trata de uma escolha propriamente dita. Apesar disso, é importante saber como os trabalhadores percebem as ações executadas pelas autoridades públicas. No item a seguir, destacamos alguns elementos presentes nas falas de quatro mulheres bolivianas que trabalham na costura.

\section{AS TRABALHADORAS}

Os bolivianos que chegaram ao Brasil a partir dos anos 1980, em geral, têm pouca qualificação profissional e igual recurso financeiro (DA SILVA, 2008), e no início da década de 1990 surgiram as primeiras denúncias de trabalho escravo nas oficinas de costura associadas a esses imigrantes (CÔRTES, 2013). Os motivos para a vinda dos trabalhadores são variados, seja para juntar dinheiro e retornar a seu país de origem, seja para enviar recurso aos familiares que ficaram, seja para se estabelecerem em terras brasileiras.

Sara, 35 anos, chegou ao Brasil em 2004 acompanhada de seu marido, deixando sua filha na Bolívia aos cuidados dos avós. Ela morou em diversos bairros da cidade de São Paulo e agora reside em São Caetano, região metropolitana. Luz, 35 anos, chegou em 2010 com seus dois filhos. Já Carmen, 32 anos, reside em São Paulo com seu marido e seus dois filhos desde 2012, mesmo ano de chegada de Zelaide, 30 anos, casada e mãe de dois filhos. As três moram na Vila Maria Alta, bairro da Zona Norte de São Paulo com alta concentração de imigrantes da Bolívia. Conhecemos Carmen, Luz e Zelaide por meio de Quilla, nossa mediadora de campo. Já Sara foi um contato de um pesquisador da área, a única cuja entrevista não foi realizada em sua casa, mas sim em uma lanchonete ao lado da Praça da Kantuta, onde ocorre uma feira semanal com venda de produtos e comidas tradicionais da Bolívia, além de diversas atividades culturais. 
É interessante notar que apesar da existência de diferentes circuitos de produção de vestuário apresentado na seção anterior, para as bolivianas entrevistadas o destino final das peças produzidas não pareceu ser relevante. A informação que elas detinham em relação às roupas que costuravam era a de que brasileiros ou coreanos eram responsáveis por entregar o tecido e, posteriormente, buscar as encomendas. Em relação às ações fiscais, nenhuma delas foi resgatada enquanto executavam seus trabalhos em frente à máquina de costura, mas já "tinham ouvido falar" sobre o assunto. Somado a isso, de acordo com suas descrições, todas passaram por situações que vão ao encontro daquelas descritas no artigo 149 do Código Penal. Ao longo das entrevistas, foi possível notar que as informações que elas detêm acerca dos procedimentos das fiscalizações e de suas consequências para os costureiros não reflete necessariamente o que ocorre na prática. Nas palavras de Carmen,

Ellos [a fiscalização] siguen a la firma. Si yo trabajo con una firma que no paga sus impuestos, van hasta su oficina y pegam todo el servício que está ahí, y colocan multa que la empresa tem que pagar. Con costureiros nos prejudican también, porque ellos ensucian el documento (Entrevista realizada em 29/06/2017).

Luz nos explicou também que se o dono da oficina não tem Cadastro Nacional de Pessoa Jurídica (CNPJ), os fiscais confiscam as máquinas, fecham as oficinas e, se encontram bolivianos sem documento, estes são deportados. Ela não conheceu ninguém que fora obrigado a sair do país, mas viu isso acontecer pelo noticiário da televisão. O receio de deportação mencionado pode ser justificado pelo fato de que, até meados dos anos 2000, a atuação dos agentes de estado visava à responsabilização dos próprios migrantes (CÔRTES, 2013). Logo, "a orientação jurídica para resolver a questão caminhava ao lado da criminalização das migrações, tendo como consequência a deportação" (MIRANDA, 2016, p. 206).

O medo de serem obrigados a sair do país dificultava ou impedia a denúncia de exploração ou tráfico por parte dos trabalhadores que desejavam fazê-la. Diante dessa situação, o Conselho Nacional de Imigração (CNIg) criou uma norma ${ }^{7}$ em 2010 que protege os imigrantes considerados vulneráveis e determina que estes sejam amparados pelas autoridades nacionais. Mesmo assim, a denúncia por parte dos próprios costureiros, apesar de existir, não é comum. Segundo a socióloga Patrícia Tavares de Freitas (2008), trata-se de uma questão complexa, que envolve relação de exploração e gratidão, jogos ambíguos entre subordinação e agência, uma vez que, na maioria das vezes, donos ou donas das oficinas são compatriotas, quando não parentes, dos trabalhadores.

Durante a realização das entrevistas, a ex-patroa de Luz, de nacionalidade coreana, havia sido denunciada por um casal de bolivianos devido à ausência de registro na carteira de trabalho referente aos dois anos trabalhados na oficina de costura. Diante da denúncia, a empregadora pediu que Luz testemunhasse em seu favor e, apesar de saber que a dona da oficina não cumpria com os acordos feitos oralmente, "ela sí, ha hecho trampa", havia um sentimento de gratidão, pois quando esteve desempregada, foi graças ao trabalho oferecido pela coreana que conseguira colocar comida em sua casa. Em conclusão, Luz decidiu não testemunhar a favor ex-patroa, porém, o motivo para tal foi o receio de uma possível retaliação do casal de bolivianos, e não pelas condições de trabalho às quais ela e os responsáveis pela denúncia eram submetidos.

\footnotetext{
7 Resolução Normativa 93, que dispõe sobre a concessão de visto permanente ou permanência no Brasil a estrangeiro considerado vítima do tráfico de pessoas.
} 
De modo geral, o que vem à mente delas em torno da fiscalização é uma percepção difusa do resultado das atuações conjuntas, sem discernimento do papel específico de cada órgão público. A ideia comum é a de que a atuação das autoridades não as beneficia nem as protege. Segundo Carmen, "si pierdes su dinero con la fiscalización, nunca más vuelves a levantar y quedas en Brasil". Ao perguntar a Luz sobre que ocorre quando há fiscalização nas oficinas, ela, que não possui seu o próprio instrumento de trabalho e está em situação regular no país afirmou que "si la fiscalización va cerrar la oficina, normal! Puedo ir a trabalhar a otra oficina". Quando entramos neste assunto com Zelaide, a boliviana desconhecia o que ocorria com os costureiros e por ter as próprias máquinas se preocupou: "¿Y cuándo son así familias? En mi caso... Eu trabajo para sobrevivir, para mis hijos también y ¿Qué tal si me entra una fiscalización?”.

Diversos fatores contribuem para a desconfiança dos trabalhadores em relação à fiscalização, tais como a barreira linguística, o desconhecimento da legislação brasileira e a ausência de informação acerca das possíveis consequências da entrada da físcalização na oficina. Para os imigrantes, o Brasil continua sendo um lugar de oportunidades quando comparado a seu país de origem. De acordo com Carmen, é complicado encontrar trabalho para quem não estudou na Bolívia, "aqui si trabajas, hay dinero, pero allá no". Outra vantagem é o fato de seus filhos terem acesso aos estudos e à saúde, apesar do preconceito, seja por parte dos colegas de escola, seja pelos profissionais de saúde, que precisam enfrentar.

Não menos importante é o fato de a percepção das imigrantes em relação ao próprio trabalho nem sempre se alinhar com a visão das autoridades. Exemplo disso é a posição de Luz sobre o fato de as oficinas de costura serem, ao mesmo tempo, local de trabalho e de moradia. Nesses ambientes, o dono da oficina, geralmente conterrâneo ou parente dos outros costureiros, é responsável pelo fornecimento de comida, com exceção do jantar do sábado e das refeições do domingo, quando, geralmente, os trabalhadores não costuram. Para esses pequenos empregadores, essa lógica de funcionamento é uma forma de baratear o custo e controlar a força de trabalho. Por outro lado, o sistema acaba sendo oportuno aos trabalhadores recém-chegados, pois estes nem sempre estão regularizados, têm dificuldade com a língua portuguesa e o valor cobrado para morar na oficina é menor do que o de um espaço alugado de forma independente. De acordo com Luz, "trabajo todo misma cosa. Cuando trabajas con boliviano te dan comida, te dan casa y tu solo costuras". Para ela, morar e trabalhar no mesmo local convém para quem está sozinho e não tem filhos, pois não é necessário pagar aluguel nem gastar com comida. Dessa forma, é possível juntar algum dinheiro:

Se uma prenda de la loja cobra, digamos, sete reais. Ai ele [dono de oficina] paga la mitad. Porque la mitad saca para el aluguel, otro tanto saca para água, luz y otro tanto para la comida. Entonces al funcionário que ha costurado la prenda toda completa, ele dá três reales (...). Se você trabajas desde $7 \mathrm{~h}$ hasta $1 \mathrm{~h}$ saca mais. Todo para vos, porque no saca para comida, nada (Entrevista realizada em 05/09/2017)

A situação apresentada por Luz, no entanto, não envolve a dívida contraída ilegalmente durante a viagem da Bolívia para o Brasil. Ela mesma nos contou que ao chegar ao Brasil precisou trabalhar seis meses para seu primo, dono de oficina, sem receber nada. Além disso, assim que teve possibilidade, deixou de morar em oficinas, a fim de garantir maior liberdade e segurança para seus dois filhos. Porém, sua situação financeira mudou: "Eu que estoy ganando del brasilero [dono da oficina em que trabalha] 1.300 reales tiene que salir para comida, aluguel...Yá no quedo con nada"

Ao discorrerem sobre suas experiências laborais, as trabalhadoras reconhecem a existência de prazos a serem cumpridos, que sem isso não recebem e, se não aceitarem as 
condições impostas, sempre haverá outra pessoa para costurar em seu lugar, mas isso não necessariamente se enquadra no que elas entendem por trabalho escravo. Contudo, se por um lado há a afirmação da vontade individual, por outro os próprios trabalhadores reconhecem seu baixo poder de negociação frente às condições impostas. Nas falas das entrevistadas, foi possível verificar também uma dubiedade entre o desejo de produzir mais e a pressão realizada pelo dono da oficina.

Antes de adquirir a própria máquina, Zelaide afirmou que "cuando no terminamos el jefe se enoja. Entonces, para no chamar la atención, seguimos haciendo, trabajamos hasta tarde. Pero también para nosotros el dinero que él paga es más alto". Ela contou também que ao chegar as encomendas, olhava prontamente para a pilha de tecidos para calcular quanto receberia pelo trabalho. "Levantaba temprano por la consciência de ganar un poquito más". Quando acabava sua tarefa, oferecia-se para executar outras atividades, como passar a roupa. Carmen nos contou que em seu primeiro local de trabalho no Brasil, seu chefe dizia: "Vamos a trabajar de $7 \mathrm{~h}$ hasta las $21 \mathrm{~h}$. No podia pasar de eso si no el vecino se molesta [do barulho das máquinas]". No entanto, como desejava seguir até mais tarde, levava a máquina para os fundos da casa e costurava até meia-noite "por ganar dinero para volvernos rápido a Bolivia". Sara mencionou que sua primeira experiência de trabalho no país foram os piores meses de sua vida. Trabalhava das $7 \mathrm{~h}$ até meia-noite, de segunda a sábado. Domingo era opcional, mas como "eu vim para trabalhar, não vim pra descansar nem de férias, trabalhava de domingo a domingo". Em seu entender,

Trabalho escravo são aquelas crianças que estão quebrando castanha ou estão nas minas de carvão. São crianças! A gente já é adulta, a gente sabe o que quer. O que a gente faz é ganhar a vida, o que a gente faz é conseguir as nossas metas, os nossos objetivos, comprar as nossas coisas, sabe? O nosso é trabalho duro... (Entrevista realizada em 05/07/2017).

Por meio das falas expostas anteriormente, é possível perceber que o significado de trabalho escravo atribuído pelas trabalhadoras é distinto do conceito presente no artigo 149 do Código Penal, sob o qual as autoridades públicas se baseiam para caracterizar o crime. Isso reflete também na percepção dessas mulheres de que a fiscalização não as beneficia, uma vez que ao interromper a situação de violação, poucas alternativas de emprego e renda lhes são dadas.

\section{CONSIDERAÇÕES FINAIS}

Apesar de a repressão ao crime ser essencial para barrar violações de direitos humanos e punir os responsáveis por elas, a política pública de combate ao trabalho escravo, que também prevê ações de prevenção e reinserção dos resgatados ao mercado de trabalho, permanece com o desafio de integrar tais ações de modo a possibilitar alternativas reais de trabalho digno aos trabalhadores. Importa ressaltar que essa questão não passa despercebida pelo poder público e pelas organizações da sociedade civil que trabalham com o tema. Ainda assim, trata-se de um problema complexo, que envolve, além de um trabalho articulado, um questionamento acerca da organização produtiva do setor.

Inserir no debate a opinião de mulheres bolivianas sobre as operações de fiscalização pode contribuir para a reflexão de uma política pública que dialogue com as necessidades dos trabalhadores imigrantes. Como foi apontado na introdução, este artigo traz uma abordagem inicial e abre caminhos para que futuros estudos sejam realizados com uma amostra maior e mais heterogênea de trabalhadores e trabalhadoras que sobrevivem da costura na cidade de São Paulo. 


\section{REFERÊNCIAS}

BRASIL. Presidência da República. Secretaria de Direitos Humanos. 10 anos de CONATRAE: trabalho escravo e escravidão contemporânea. Brasília: SDH, 2013.

BIGNAMI, Renato. Trabalho escravo contemporâneo: o sweating system no contexto brasileiro como expressão do trabalho forçado urbano. In: VELLOSO, Gabriel.; FAVA, Marcos Neves (Org.). Trabalho escravo contemporâneo: o desafio de superar a negação. 2. ed. São Paulo: LTr, 2011.

CÔRTES, Tiago Rangel. Os migrantes da costura em São Paulo: retalhos de trabalho, cidade e Estado. 2013. Dissertação (Mestrado em Sociologia) - Faculdade de Filosofia, Letras e Ciências Humanas, Universidade de São Paulo, São Paulo, 2013.

DA SILVA, Carlos Freire. Trabalho informal e redes de subcontratação: dinâmicas urbanas da indústria de confecção em São Paulo. 2008. Dissertação. (Mestrado em Sociologia) Faculdade de Filosofia, Letras e Ciências Humanas, Universidade de São Paulo, São Paulo, 2008.

FIGUEIRA, Ricardo Rezende. A persistência da Escravidão ilegal no Brasil. Lugar Comum, n. 33-34, p. 105-121.2011. Disponível em: http://www.gptec.cfch.ufrj.br/pdfs/A_persistencia_ da_Escravidao_ilegal_no_Brasil.pdf. Acesso em: 8 jul. 2017.

FILGUEIRAS, Vitor. Trabalho análogo à de escravo e o limite da relação de emprego: natureza e disputa na regulação do Estado. In: FIGUEIRA, Ricardo Rezende; PRADO, Adonia Antunes; GALVÃO, Edna Maria. (Org.). A universidade discute a escravidão contemporânea: práticas e reflexões. Rio de Janeiro: Mauad X, 2015.

FREITAS, Patrícia Tavares de. Migrações Internacionais Imigração e empreendimentos econômicos - o circuito de confecção e comercialização de roupas em torno de imigrantes coreanos e bolivianos na cidade de São Paulo. In: ENCONTRO ANUAL DA ANPOCS, 32, 2008, Caxambu. Anais [...]. Caxambu: ANPOCS, 2008.

MARTINEZ, Vanessa Nogueira. Equidade em saúde: o caso da tuberculose na comunidade de bolivianos no município de São Paulo. 2010. Dissertação. (Mestrado em Saúde Pública) Faculdade de Saúde Pública, Universidade de São Paulo, São Paulo, 2010.

MCGRATH, Siobhán. Many chains to break The Multi-dimensional Concept of Slave Labour in Brazil. Antipode, v. 45, n. 4, p. 1005-1028, 2013. Disponível em: http://onlinelibrary.wiley. com/doi/10.1111/j.1467-8330.2012.01024.x/full. Acesso em: 20 dez. 2017.

MERCANTE, C. A terceirização na indústria de confecções e a reincidência do trabalho análogo à de escravo. In: ENCONTRO NACIONAL DA ABET, 16, 2015, Campinas. Anais [...]. Campinas: ABET, 2015.

MIRANDA, Bruno. Entre coerción y consentimiento: la circulación de trabajo no-libre boliviano visto desde un taller de costura de Bom Retiro, São Paulo. 2016. Tese. (Doutorado em Ciências Políticas e Sociais) - Instituto de Investigaciones Sociales, Universidad Nacional Autónoma de México, Cidade do México, 2016.

REPÓRTER BRASIL. Monitor \#3 Fast Fashion e os direitos do trabalhador. 2016a. Disponível em: http://reporterbrasil.org.br/wp-content/uploads/2016/08/Fast-Fashion_VFinal. pdf. Acesso em: 13 fev. 2018. 
REPÓRTER BRASIL. Trabalho escravo nas oficinas de costura. 2016b. Disponível em: $\quad$ http://reporterbrasil.org.br/wp-content/uploads/2016/06/Fasc\%C3\%ADculoConfec\%C3\%A7\%C3\%A3o-Textil_Final_Web_21.01.16.pdf. Acesso em: 10 fev. 2018.

REPÓRTER BRASIL. Escravo, nem pensar! no município de São Paulo 2018/2019. 2020. Disponível em: http://escravonempensar.org.br/wp-content/uploads/2020/06/enp_sp_20182019.pdf. Acesso em: 26 jun. 2020.

SÃO PAUlO (Cidade). Câmara Municipal de São Paulo. Relatório final da comissão parlamentar de inquérito para apurar a exploração de trabalho análogo ao de escravo. 2006. Disponível em: http://www1.camara.sp.gov.br/central_de_arquivos/vereadores/CPITrabalhoEscravo.pdf. Acesso em: 10 nov. 2017.

SILVANA, Cristina. Circuito espacial produtivo das confecções e exploração do trabalho na metrópole de São Paulo. Os dois circuitos da economia urbana nos bairros do Brás e Bom Retiro (SP). 2012. Tese (Doutorado em Geografia) - Instituto de Geociências, Universidade Estadual de Campinas, Campinas, 2012.

Recebido em: 01/03/2018 Aceito para publicação em: 02/07/2020 